How Emotions Enter into Decision Making: A Novel Categorization of Types of Emotions

\author{
NOT PEER REVIEWED
}

Emir Efendić*

Eindhoven University of Technology, Department of Industrial Engineering and Innovation

Sciences, Human Performance Management Group, Eindhoven, The Netherlands, De Zaale, 5612 AJ Eindhoven, P.O. Box 513

*Correspondence should be addressed to efenemir@gmail.com or e.efendic@tue.nl 


\begin{abstract}
Research in how emotions impact decision making is growing and the corresponding literature is often organized around types of emotions. These types can be thought of as labels that categorize how emotions enter into decision making. Examples include “expected”, “integral”, or “incidental” emotions. Taking a closer look at several of these categorizations however, one is confronted with discord and a considerable number of inconsistencies in naming conventions, definitions, scope of the categorizations, as well as a lack of clear approach to how emotions might enter into decision making. Given the ubiquity of these categorizations, in this paper, we conduct a review of types of emotions, we address some of the inconsistencies, and we present a new way of categorizing how emotions enter into decision making - one where emotions are categorized in relation to the decision and affective components of the decision making process. We discuss how this new categorization deals with the identified inconsistencies and ways in which it can be conducive to developing novel theoretical and empirical investigations in how emotions impact decision making.

Keywords: Decision-Making; Types of Emotion; Integral Emotions; Expected Emotions; Incidental Emotions;
\end{abstract}

Words abstract: 175 


\section{How Emotions Enter into Decision Making: A Novel Categorization of Types of Emotions}

Emotions have an undeniable impact on judgment and decision making (JDM). It has been shown that emotions can, dependent on the decision situation, lead both to suboptimal (e.g., Ariely \& Loewenstein, 2006; De Martino, Kumaran, Seymour, \& Dolan, 2006; Mikels, Cheung, Cone, \& Gilovich, 2013; Ratner \& Herbst, 2005) and superior (e.g., Bechara, 1997; Koenigs \& Tranel, 2008; Mikels et al., 2010; Shiv, Loewenstein, Bechara, Damasio, \& Damasio, 2005) decisions. Furthermore, interest in emotions and the impact that they have on JDM has been on the rise. Lerner, Li, Valdesolo, and Kassam (2015, supplemental material), for instance, found that the yearly output of published papers on this topic increased by an order of magnitude from 2001 to 2013.

Most researchers in this domain seem to agree that there are several ways in which emotions can enter into decision-making. As a result, distinctions have been made between different types of emotions (e.g., integral, incidental, expected, immediate, etc.) which categorize the ways emotions can enter into JDM. Nearly every major review of the emotion and JDM literature highlights types of emotions and theoretical frameworks are often-times distinguished dependent on the type of emotion they focus on. For example, the "appraisal tendency framework” (Lerner \& Keltner, 2001) focuses on incidental emotions while “decision affect theory” (Mellers, Schwartz, Ho, \& Ritov, 1997) focuses on anticipated emotions. Types of emotions are also referenced in empirical research. For example, attempts to reach a better understanding of the mechanisms of the emotional impact on decision making have incorporated different types of emotions into complex mediation models (Charpentier, De Neve, Li, Roiser, \& Sharot, 2016; DeWall, Baumeister, Chester, \& Bushman, 2016) and coherent types of emotion 
categorizations are useful in building more comprehensive models of human decision making (cf. Lerner et al., 2015, the EIC model).

Taking a closer look at the literature however, we findd that types of emotions are often presented in largely different ways with inconsistencies in naming conventions, definitions, and scope. Because of this, we consider it useful to conduct a review of types of emotions from a “bird's eye perspective”, identify the commonalities, introduce the reader to the complexities and importance of these categorizations, and highlight some of the inconsistencies and variabilities. In doing this, we also noticed that there is a lack of a clear approach on how best to categorize the way emotions enter into decision making. Using the insights from our review, we present a new approach to categorizing how emotions enter into JDM. We discuss how this approach can reconcile some of the inconsistencies, lead researchers to be more mindful of the decisionmaking process, and lead to new and interesting research venues.

\section{Reviewing the various type of emotions categorizations}

In order to illustrate the way types of emotions have been presented in the literature, we center our attention on reviews of the emotion and JDM literature. Even though we focus on other reviews, we do not consider this to be a "review of reviews”. Our main "unit of analysis", so to speak, remains the type of emotion, not the review itself. We limit our selection to the last two decades of emotion and JDM research and the findings that are highlighted in this time period. We similarly set up some limitations. First, the reviews we focus on must cover a wide range of emotion and JDM areas. For instance, while the “risk-as-feelings” paper by Loewenstein, Weber, Hsee, and Welch (2001) is an important paper on the impact of emotions on decision making, we do not take it into account here given its focus on risky decision 
making. ${ }^{1}$ Second, we only take into account reviews published as journal articles or those that are part of handbooks. Third, we maintain our focus on reviews from the fields of psychology and (behavioral) economics. This leaves out reviews from affective neuroscience or neuroeconomics (e.g., Phelps, Lempert, \& Sokol-Hessner, 2014), which, in any case, focus more on neural circuits and tend not to deal that much with types of emotions. We do not claim that all possible reviews that have in some way incorporated types of emotions have been selected here, but we do feel that this is a representative batch. Our search, given the constrictions we set up, resulted in ten reviews which provide an illustration of the field in its relevance and the JDM areas covered.

\section{A bird's eye perspective on types of emotions}

The ten reviews we selected are shown in Table 1., which also contains short summaries of the types of emotions as they were presented in each review.

\section{[Insert Table 1. around here]}

What Table 1 . is also, hopefully, conveying are the apparent distinctions between these reviews. This "bird’s eye perspective” allows us to see that the various times where types of emotions have been utilized, their presentation was not uniform. In the next section, we will highlight some commonalities and identify the types of emotions which have been presented across the years. The goal is to introduce the reader to these categorizations, but also to get a general sense of how researchers thought about the ways in which emotions enter into decision making.

\footnotetext{
${ }^{1}$ We ought to be fair here and mention that Loewenstein and colleagues (2001) do introduce a distinction between "anticipatory" and "anticipated" types of emotions, but only to highlight that to the extent that decision making research has taken into account emotions, it was only the anticipated ones and that anticipatory emotions can also have an important impact as well.
} 


\section{Types of emotions}

\section{Pre-decision emotions}

A lot of work in emotion and JDM distinguished emotions simply on whether they are active prior to the actual decision. These “pre-decisional emotions”, as the name suggests, are emotions that impact decisions before the decision is actually made. This category is somewhat vague and is better thought of as an umbrella term, as it takes into account many different varieties and types of emotions. Vastfjall and Slovic (2013), make this explicit when they say that current mood, anticipatory, and anticipated emotions (we describe each of these types in more detail below) all fall under pre-decisional emotions. Thus, any emotional or affective reaction that is in some way present or activated before the decision itself, can be included in pre-decisional emotions. Because this is a general (i.e., umbrella) type of emotion, we do not discuss it as thoroughly as we will touch upon several of the types that fall under it. However, it might be interesting to mention an interesting addition to pre-decisional emotions, introduced by Schwarz (2000), but not mentioned in other reviews (of the ones that we have selected here). This is the concept of “memories of past affect". An example would be when individuals extract meaning from past emotional experiences, e.g., the peak or end of an affective experience (Fredrickson, Kahneman, Hayes, \& Knopoff, 1993). Memories of past affect could be an interesting addition to pre-decisional emotions, but their relation with decision making needs to be made clearer. While the length of a positive or negative experience can certainly have an impact on how one evaluates that experience, it is not so clear what might be the impact on decision making per se.

\section{Emotions at the time of the decision}


The second type we see distinguished in the literature are emotions that occur at the time of making the decision, referred to in other reviews as "immediate emotions", as "decision time emotions” (Rottenstreich \& Shu, 2004), or “current emotions” (Lerner et al., 2015). The category can, again, be considered as an umbrella term as it encompasses several affective states and different types of emotions. For the definition of this type we follow Loewenstein and Lerner (2003) who defined “immediate emotions" as emotions which are actually experienced at the time of decision making and which often drive behavior into directions that are different from those dictated by evaluations of possible consequences. Schwarz (2000) also described reliance on this type of emotions as when individuals use their apparent affective response to a target as a basis for judgment, in effect asking themselves "how do I feel about this”. Examples of this type of emotion impacting decision making include mood congruency effects on judgments (Johnson \& Tversky, 1983; Schwarz \& Clore, 1983) or the impact of specific emotions like anger and sadness on risky decisions (Lerner, Li, \& Weber, 2013; Lerner \& Keltner, 2001; Yang, Saini, \& Freling, 2015). Loewenstein and Lerner (2003) further separated immediate emotions into those that can exert a "direct impact”, meaning they are not mediated by changes in other emotions or in cognitive processing (e.g., an emotion impacting a decision without altering the person’s perceptions of decision attributes like probability and value), and those that can exert an "indirect impact” (e.g., where emotions do alter the person’s expectations about the probability or desirability of future consequences or by changing the way that these consequences are processed). However, this distinction is not mentioned in other reviews that we looked at, even though it could be useful in theoretical and empirical discussions focused on the mechanisms of the emotional impact on decision making (DeWall et al., 2016; Scheibehenne \& von Helversen, 2014). Direct emotions were then further subdivided by Loewenstein and Lerner (2003) on two 
levels: at "low or moderate levels of intensity", where they usually have an advisory role, and at “high intensity”, where they can overwhelm any deliberative decision making. For instance, there are multiple examples of irrational risky decision making in the presence of intense visceral emotions (e.g., Ariely \& Loewenstein, 2006; Loewenstein, 1996). Again, this distinction is not present in other reviews we selected. Notwithstanding these expansions, there is agreement that this type of emotion contains at least two sub-categories of "incidental” and "integral” emotions.

\section{Incidental emotions}

“Incidental emotions”, also designated as “background emotions” (Dunning, Fetchenhauer, \& Schlösser, 2017), are emotions which are not in any way related to the decision at hand or the object to be evaluated. Imagine your bad mood being caused by a conflict at work, with this bad mood impacting your decision for which movie to see. The cause of your bad mood does not have anything to do with your decision. Lerner et al. (2015) highlight that this type of emotion pervasively carries over from one situation to the next, impacting decisions that should, from a normative perspective, be unrelated to that emotion. Examples of this type of emotion impacting decision making can be seen in mood effects on consumer behavior (e.g., Gardner, 1985; Lee \& Sternthal, 1999) and again in studies of specific emotions. For instance, when unrelated gratitude reduces economic impatience (DeSteno, Li, Dickens, \& Lerner, 2014) or when unrelated sadness leads people to make more present-based decisions (Lerner et al., 2013). George and Dane (2016), in their review, curiously differentiated between "incidental moods” and "discrete emotions", but is seems like both of these types fall under incidental emotions as both moods and discrete emotions can be unrelated to the decision. Loewenstein and Lerner (2003) made further distinctions in incidental emotions between: “dispositional” (i.e. if someone has a tendency to react in a particular way) and "situational" (e.g. lingering, incidental moods or 
emotions - when the object of a subsequent decision bears no relation to the source of one’s anger, but the anger still impacts the decision). However, it is difficult to see how the impact on the decision might differ between these two emotion types. In both cases, the emotion is unrelated to the decision, and dispositional or situational anxiety for instance, would presumably have the same effect on a decision (although they could differ in intensity for instance; but see our categorization of how emotions can enter into decision making where we touch upon some of these issues).

\section{Integral emotions}

“Integral emotions”, on the other hand, are related to, and can stem from, the decision task at hand. Cohen, Pham, and Andrade (2008) for instance, define this type of emotion as emotions which are genuinely experienced and directly linked to the object of judgment and decision. They further go on to state that emotional responses are integral to the extent that they are elicited by features of the decision object, whether these features are real, perceived, or imagined. Imagine for instance that investing situations make you feel anxious or tense and because of this feeling you avoid or forego an investing opportunity. There are many examples of this type of emotion impacting decision making, but the finding most often associated with integral emotions is the work on the somatic marker hypothesis where it was shown that a physiological reaction to a feature of a risky choice task (the Iowa Gambling Task) was a predictor of people’s decisions and success in the task (Bechara, 1997; Damasio, 1994). Additionally, integral emotions can be very influential. An example given often is when people avoid flying and choose to drive due to their fear of planes. This can be because once integral emotions attach themselves to decision targets, they become very difficult to detach (Rozin, Millman, \& Nemeroff, 1986). 


\section{Post-decision emotions}

The third, umbrella-like type of emotion, which remains in this progression, are "postdecision emotions”, referred to in other reviews as "post-resolution” emotions (Rottenstreich \& Shu, 2004), as “emotions as a consequence of decision making” (George \& Dane, 2016), or “expost” emotions (Wälde \& Moors, 2017). This type mostly concerns emotions experienced after the outcome of a decision is known and they are also sometimes referred to as "counterfactual" or “cognitive” emotions (Vastfjall \& Slovic, 2013) due to their large dependence on certain decision outcomes. Imagine for example feeling regret after finding out that your decision lead to a win of $\$ 5$, but a different choice might have gotten you $\$ 10$. The majority of work concerning this type of emotion has been with regret and disappointment (Martinez, Zeelenberg, \& Rijsman, 2011; Zeelenberg, Van Dijk, \& Manstead, 2000). Both emotions are experienced in relation to an unfavorable outcome. The experience of regret, for instance, has been shown to lead to risk aversion and unwillingness to act (Zeelenberg, 1999). Besides regret and disappointment, other post-decision emotions like surprise and elation have also been explored (Mellers, 2001; Mellers et al., 1997). Rottenstreich and Shu (2014) proposed an interesting distinction in "post-decision emotions”; one that rests on emotions which are experienced after the decision has been made, but before the consequences of the decision are realized, i.e., "pre-resolution, post-decisional emotions". While this type of emotion is interesting, it does not seem like it was highlighted in any other review we took into account.

\section{Expected emotions}

Beyond the three umbrella-like types of emotions (pre, during, and post decision emotions), researchers have also highlighted “expected emotions”, referred to also as “anticipated emotions”. This type of emotion is present in almost all of the reviews we took into 
account and, as Loewenstein et al. (2001) argued, they have been taken into account even in classical models of decision making (i.e., models that have traditionally excluded the impact emotions might have on people’s decisions; cf. Lucey \& Dowling, 2005). Expected emotions are defined as possible future emotions taken into account when determining the expected utility of different courses of action. Examples of this type of emotion impacting decision making abound. Imagine having to choose where to book your next holiday. For a particular choice option, you expect to feel miserable there so you decide to avoid the option altogether. Expected emotions are somewhat peculiar as they constitute predictions about possible emotional consequences of decision outcomes. Therefore, they are not felt at the moment of decision making. Another way of saying this is that they are cognitive expectations about future emotions. Prototypical studies of expected emotions also involve regret and disappointment given how people might expect to feel these emotions and thus avoid certain decision options (Baumgartner, Pieters, \& Bagozzi, 2008; Connolly \& Reb, 2012). Furthermore, it is assumed that outcomes are compared to some other, counterfactual, outcomes and feelings of regret and disappointment are the result of these comparisons (Loomes \& Sugden, 1986).

\section{Anticipatory emotions}

Many reviews and empirical papers talk about “anticipatory emotions” which have also been described as “ex ante” emotions (Wälde \& Moors, 2017). Anticipatory emotions are different from expected (anticipated) emotions, in that they are not cognitive, but are actually felt. Using the same example as with the expected emotions, imagine that you are choosing where to book your next holiday. For a particular choice, your anticipatory thinking actually evokes negative reactions about a particular choice, so you avoid it and decide to go somewhere else. Again, Damasio’s (1994) work on somatic markers, can serve as an example of anticipatory 
emotions. Participants’ eloctrodermal reactions were activated before choosing, indicating a physiological and emotional reaction in response to expecting a potential outcome, making them avoid the particular deck with which these reactions were associated with. Further, Vastfjall and Slovic (2013) add to the discussion of anticipatory emotions by highlighting that mental imagery is an important aspect of their presence and activation. Some emotions are more easily imaged than others and mental imagery is often accompanied by electrodermal and visceral responses, which help bring about anticipatory reactions (Gollnisch \& Averill, 1993; Haney \& Euse, 1976; Lang, Kozak, Miller, Levin, \& McLean, 1980). Mental imagery can therefore be seen as an important determinant of anticipatory emotions.

\section{Process/task related emotions}

Another type of emotion mentioned in a couple of reviews, but falling outside of the three major umbrella types, are “process, or task-related emotions”. Rottenstreich and Shu (2004) define "process-related emotions" as those which arise from the process of making a decision. Imagine for instance that the fact of having to choose a new car out of several good options activates negative feelings which impact your choice. Cohen et al. (2008) refer to this as "taskrelated affect”, which, according to them, lies somewhere between integral and incidental emotions and refers to affective responses that are elicited by the task or the process of making judgments and decisions. A very basic example of this type of emotion would be when the aversive emotional experience of having to make trade-offs across important attributes, leads consumers to prefer avoidant options such as choosing the status quo (Luce, 1998). The converse would be the unpleasant feelings evoked when one has to forego attractive options (Dhar \& Wertenbroch, 2000). Dunning et al. (2017) similarly introduce “action-related emotions” which are described as emotions that people attach to the decision options among which they are 
choosing. They are activated when people contemplate decision options. All three types, while somewhat differently named, seem to be describing a similar phenomenon of how emotions can enter into decision making.

\section{Takeaways from reviews of types of emotions}

In the above section, we attempted to present the types of emotions that have, in some form or another, been introduced in the emotion and JDM literature. We did this by focusing on the reviews of the literature, but this does not mean that each of these types is mentioned (identified) in each of the reviews (as is visible in Table 1). Nevertheless, the selection should represent a fairly inclusive overview of types of emotions. Because we were focused on the types themselves we did not include a lot of discussion on the various empirical findings which are associated with them. Nevertheless, the reader should have gotten the general sense of how the emotional impact which can enter into decision making was categorized with each type.

Taking aside the individual types of emotions for a moment and looking across the ten selected reviews, as mentioned in the introduction, we identified several inconsistencies and differences. While it cannot be claimed that the ten selected reviews constitute a "literature", it is clear that even in such an ad-hoc selection, the differences are quite substantial. Before discussing a new approach to how one might categorize the way emotions enter into decision making, we reflect on some of these inconsistencies and differences.

The first, and most evident issue we came across is that different authors use different terms for the same type of emotion. Expected emotions are the same as anticipated emotions, immediate emotions are the same as current emotions, or emotions at the time of decision, while process-induced emotions are the same as task-induced emotions. These are just different terms for the same concept. Granted, this is inherently not that strong of an offense as terminology is 
notoriously difficult to pin down. However, it does indicate that many reviews, and correspondingly many authors, do not seem to take into account previous contributions in the literature thereby introducing confusion to the discussion of emotional impacts on decision making.

Second, as mentioned above, there are differences in which types of emotions are highlighted (i.e., taken into account) by which authors. As just one example, Rick \& Loewenstein (2008), who, by their own account, reviewed the emotion and JDM literature from an economics perspective, highlight only expected and immediate emotions (which were further subdivided into integral and incidental emotions). Contrast this with Cohen et al.'s (2008) review (which we compare because it came out the same year) who, by their own account, reviewed the emotion and JDM literature from the consumer behavior perspective, highlight, on the other hand, integral, incidental, and task-induced emotions. These differences in scope diminish the range of influence which is being discussed when talking about how emotions impact decision making. For instance, by not mentioning certain types of emotions in reviewing the literature, authors are implicitly narrowing their area of impact. Why wouldn't researchers in the field of economics, for instance, be interested in the impact of anticipatory or process-related emotions? Which types of emotions a researchers is introduced to, should not depend on which particular review the researchers reads, if indeed types of emotions are an important part of the emotion and JDM literature. Again, these differences may not present a strong offense, and one hopes that researchers would gather more information than from just one review, but it can have negative ramifications.

Third, not all authors are on the same page when it comes to how types of emotions can overlap. What is meant by “overlap”? Specifically, upon closer reading, it becomes clear that 
how emotions enter into decision making can crossover and a certain type, which is separated as its own category, can sometimes fall under a different category as well. For instance, most reviews state that integral and incidental emotions are considered as sub-categories of immediate emotions. However, many reviews, do not state that expected emotions can also fall under the category of integral emotions because they are evoked, or related to, the decision task at hand. ${ }^{2}$ Consider another example. If "pre-decision” emotions are those that are present before the decision is made, then "incidental emotions" (which fall under the category of immediate emotions), which are defined as being unrelated to the decision at hand, can also be considered as pre-decisional. This is because, as incidental, they cannot be activated by the decision task so their presence had to have started at some “pre-decision” time. Similar with anticipatory emotions which can also be considered as “integral emotions” given that integral emotions denote those which are related to, or stem, from the decision at hand. Cohen et al. (2008) address this directly by introducing a division of integral affect between "anticipatory”, and “anticipated”, but this is not seen in any of the reviews we took into account. Interestingly, in the process of discussing integral affect, a very recent review by George and Dane (2016) inadvertently comes upon the importance of highlighting this overlap, but the authors do not address it in their categorization of types. They state that studying integral affect can be difficult given that affect can be integral to the decision-making process, but that there is also the potential that the decision-making task itself differs across levels of integral affect (i.e., taskrelated emotions are technically also integral emotions). Notice that this is an important insight for a researcher planning a study. When she tries to evoke emotions by introducing several

\footnotetext{
${ }^{2}$ Meaning that such insights are not mentioned specifically in the reviews. One could argue that this is common knowledge and that is why authors forego stating it explicitly, but this does not seem to be the case.
} 
options for the decision maker, does she also take into account how each of these options can produce an emotional reaction? Vastfjall \& Slovic (2013) attempted to address this somewhat in their review. They presented types of emotions as being along three dimensions: time of decision (pre- vs. post-decisional), time of emotion (immediate vs. expected), and affect-decision relationship (integral vs. incidental) thus highlighting the potential for overlap. Looked at types in this sense, expected emotions can be considered to be part of expected, pre-decisional, and integral emotions. Nevertheless, directly referencing this sort of categorization has not been observed in the other reviews we took into account here.

Fourth, in several of the reviews, there are certain issues and imprecisions that accompany the definitions of the types. Granted, examples of this are subtle, but important nonetheless. For instance, Rick and Loewenstein (2008) state that integral emotions arise from thinking about the consequences of the decision. However, this also corresponds with a definition of anticipatory emotions. There seems to be no mention of how integral emotions were, in other reviews, defined as arising from, or due to, the exposure to the decision task itself (Cohen et al., 2008; Lerner and Loewenstein, 2003). A similar issue can be seen when Loewenstein and Lerner (2003) define immediate emotions as being determined by two factors of anticipatory and incidental influences. In other reviews, these “influences” are simply defined as types of emotions in themselves.

\section{A new categorization of how emotions enter into JDM}

Based on insights gained from the "bird's eye perspective” on types of emotions, we believe that there is a parsimonious way of thinking about how emotions enter into decision making - one that could help alleviate some of the inconsistencies we highlighted in the previous section, but also aid researchers who wish to pose new and interesting questions about the 
emotional impact on JDM. We noticed, after reviewing previous categorization attempts, that there seems to be no overarching thread or rule that defines how one might categorize the ways in which emotions can enter into decision making. In other words, no unique strategy is utilized. What seems to have been the procedure so far, is akin more or less to an "after-the-fact" approach. Namely, researchers would enumerate different types of emotions as they try to fit the corresponding empirical findings into specific categorizations. Naturally, what happens when one uses such an approach is that, dependent on the empirical literature the author(s) review, their disciplinary focus, or expertise with emotion or decision making, one ends up with different categorizations every time. We believe that a better-organized approach would actually present the researcher with a "before-the-fact" strategy of how to categorize the emotional impact on decision making. This should diminish the possibilities of ending up with different categorizations.

Our proposal is that researchers categorize how emotions enter into decision making by identifying how they relate to the various features of a decision component, and to the various features of an affective component, respectively. To provide a simple example, an emotion that a researcher is interested in might relate to the potential outcome of a decision (outcomes are an important feature of the decision), but it also might relate to how specific or diffuse it is (an important affective feature). Similarly, a different emotion might relate to the decision task (feature of the decision), to a period of time after the choice is made (decision feature again), and it might relate to whether it is actually felt or not (affective feature).

As we present it in the examples above, the decision and the affective component consist of a number of features. To provide more detail, we propose that each feature has a range. We 
summarize the features and their range Table 2. and we discuss each of the two components in more detail below.

[Table 2. about here]

\section{Affective component}

Different affective features, like intensity, have previously been highlighted and shown to have an impact on decision making (Ariely \& Loewenstein, 2006; Lerner \& Loewernstein, 2003). However, when categorizing how emotions enter into decision making, the affective component was not highlighted nearly as much as it could have been. We identify four features that the researcher might consider when thinking about how the emotional impact on decision making is related to the affective component. The first feature we highlight is the phenomenology of the emotional experience (cf. Lambie \& Marcel, 2002). This feature refers to and ranges from those emotions that are actually felt to those that are not felt. As it has been argued in other categorizations of types of emotions, an emotional impact might not always be felt in order for it to have a strong effect on a people’s decision making. Many of the types of emotions that were presented in other reviews relied on this distinction, even though it was not explicitly emphasized. For instance, expected (anticipated) emotions are not felt, they are expected to be felt in the future. Conversely, anticipatory emotions are felt, just like incidental or process-related emotions. Therefore, separating, or better yet, identifying the emotional impact simply on whether it is felt or not is a highly relevant distinction to the impact of emotions on decision making.

The second feature we highlight is awareness. This feature refers to, and ranges from those emotional reactions that the decision maker is fully aware of, to those that the decision maker is unaware of. For instance, in the somatic marker hypothesis, there has been considerable 
debate on the "unconscious" aspect of the markers and whether people are actually aware of why they, at a certain point, start choosing the correct decks in the Iowa Gambling Task (cf. Maia \& McClelland, 2004; Shiv et al., 2005). We consider it important that, when identifying the emotional impact on decision making, researchers pay attention to defining how and whether people are aware of the emotion. This goes in line with a classic finding which states that the effect of mood, for instance, can disappear once people are made aware of it (Schwarz \& Clore, 2003). Focusing and distinguishing the emotional impact on this feature might also help raise interesting research ides. While it has been shown for instance, that anger impacts decision making in a number of ways (e.g., Lerner \& Tiedens, 2006), an interesting research venue might be to study how anger's effects change dependent on the decision maker's awareness of his/her angry state?

The third feature we highlight is emotion intensity. This feature can obviously range from low to high, with different effects on decision making. Low intensity emotions have been suggested to relate to an advisory role that emotions might have, meaning that they do not overcome the decision-making process, but are complementary to it (Caruso \& Shafir, 2006; Dunn et al., 2010). This would be akin to using the emotion as a guide for decision making, as suggested by the affect heuristic (Slovic, Peters, Finucane, \& MacGregor, 2005) or the "how-doI-feel-about-it” heuristic (Pham, Cohen, Pracejus, \& Hughes, 2001). In the high intensity range, on the other hand, it relates to emotions that could overcome the decision-making process in its entirety, leading the decision maker into unexpected choices. This includes research done on high intensity reactions like those evoked by accidents, unprecedented and highly emotional events like terrorism and so on (Rottenstreich \& Hsee, 2001; Sunstein \& Llewellyn, 2003). 
Finally, the fourth affective feature we highlight is emotion specificity. This feature can also range from low to high. We refer to low specificity affective qualities as those that are diffuse with not so clear causes (usually differentiated purely on valence or arousal) such as moods or simple affective cues (Russell, 2003; Winkielman, Knutson, Paulus, \& Trujillo, 2007; Yik, Russell, \& Barrett, 1999). We refer to high specificity affective qualities as those that are discrete, specific, and have a precise cause (Lerner, Li, \& Weber, 2013; Lerner \& Keltner, 2001). The reason we consider this feature to be important is that the specificity of the emotion can have a strong impact on the decision. For instance, due to different appraisals that are associated with various specific emotions (Scherer, 1999; Smith \& Ellsworth, 1985), the appraisal tendency framework predicts different effects of emotions such as anger or fear on the decision, even though both emotions are negatively valenced (Lerner \& Keltner, 2000). Similarly, in the low register, whether the emotional impact is differentiated purely on valence or arousal for instance, can also have different effects on the decision. For example, in certain situations, arousal has been found to impact ad evaluations, whereas valence has not (Gorn, Tuan Pham, \& Yatming Sin, 2001). Similarly, arousal has been found to help discriminate between good and bad decks in the Iowa Gambling Task, but not between good and bad decision making in general (Jenkinson, Baker, Edelstyn, \& Ellis, 2008).

\section{Decision component}

We similarly identify four features of the decision component we consider as important when categorizing how emotions enter into decision making. Interestingly, several of the types of emotions that we have reviewed have indirectly differentiated how emotions enter into decision making by the specific features of the decision (pre-decisional and post-decisional emotions are an obvious example). However, we make this explicit and the first feature we 
highlight is the time of decision. We recognize that this might be a crude delimitation as, in our opinion, there are some issues to when one could say that a pre-decisional emotion stops being pre-decisional and can be designated as immediate. However, time of decision is an essential feature to differentiating the emotional impact. In order to be more precise though, we define the mid-point in this feature's range as the actual decision choice (i.e., the point where the choice is made). Therefore, any emotion that is entering into decision making before this mid-point should be considered as pre-decisional, and any emotion that is entering after this mid-point should be considered as post-decisional.

The second feature we highlight is the decision situation relationship. This feature is based on the distinction between integral vs. incidental emotions, which most authors consider as crucial given that it was highlighted in almost all of the reviews we selected. Consequently, we consider that this feature ranges from totally unrelated to the decision situation, to caused and stemming from the decision situation. In the latter case, the emotions' relationship with the decision should be concrete, identifiable, and easily traceable to the decision situation (Pham, 2007). In the former case, it should be clear that there is no direct relation with the decision situation whatsoever and that the emotion's elicitation is actually related to some other event or situation.

The third feature we highlight concerns the decision element. One can regard the decision as consisting of different elements. For instance, Hastie (2001) has suggested that decisions consist of courses of action (e.g., one has to actually choose or decide something) and potential outcomes or consequences of these actions (Hastie, 2001). Along with these two, we also consider that an important element of the decision is the actual decision task (as highlighted by task-related and process-related emotions). Emotions could attach to each of these three elements 
and we consider that this feature ranges from task, action, to outcome. This feature could also help researchers ask novel questions about the emotional impact on decision making. For instance, focus could be put not only on emotions that relate to these three ranges, but also study how emotions can enter between these ranges, say between receiving information on the decision task, but before the outcome of that decision can become known. Analogously, recent findings have been showing that for instance, people’s risk preferences (i.e., whether one is generally risk averse or risk seeking) change dependent on which task one uses to measure these preferences (Pedroni et al., 2017). Decision tasks and the emotions which could enter into decision making because of them, are an important factor that should receive much more attention in future research.

The forth feature we highlight is the decision actor. While decision making is most often discussed in terms of people being the decision makers themselves, there is also the possibility that people will be at the receiving end of somebody else's decisions. This feature can range from decision actor to decision receiver and it can also help researchers extend the work in the emotion and JDM domain. One might also infer information about a persons decision, dependent on how long this person took to get back to you or dependent on how much time passed between you providing them with a decision (Van de Calseyde, Keren, \& Zeelenberg, 2014). With this feature, we see potential in asking interesting questions about the role of emotions which enter decision making between receiving some other person's decision, and making one’s own. For instance, many negotiating situations require people to not only make their own decisions, but also to react and await decisions from others. Emotions could enter these situations in various ways and this feature makes a clear distinction for researchers who wish to study such impact.

\section{Advantages of the new categorization}


In this section, we summarize the main points that provide additional justification for the benefits of our suggested approach to categorizing the way emotions can enter into decision making. We first discuss how it solves the inconsistencies we have identified in the literature. Several of the differences we found between the reviews of the emotion and JDM literature can be, in our opinion, accounted for (explained by) which of the two components the researchers were more focused on. For instance, Loewenstein and Lerner (2003) devoted considerable focus (at least more than the other reviews) to the affective component, resulting in their review containing type categorizations that were related to the intensity of the emotion, the dispositional quality, or the directness and indirectness of its impact. On the other hand, when authors focused more on the decision component, this resulted in reviews containing categorizations such as process or task-related emotions (Cohen et al., 2008), emotions that might impact the decision after it has been made, but before the consequence is known (Rottenstreich \& Shu, 2004), or emotions that might attach to the actions of a decision (Dunning et al., 2017). By saying that the emotional impact can be related to and should be defined with these two components - decision and affect - in mind, we make it explicit that the emotions can enter into the process in multiple ways, and that the way they enter it is not necessarily limited to a few types. A particular emotional impact might be, for instance, felt, highly specific, related to the decision task, and pre-decisional. Incidentally, this also addresses the issue of how types of emotions can overlap. The suggested approach also untangles the problem of different naming terms being used by different authors. Because the approach is relational, i.e., the emotional impact is defined in relation to one of the two components, the naming convention should not be important as long as the impact is defined properly. This also solves the issue of different definitions being present across some of the reviews. In addition to the emotional impact being defined in terms of how it 
relates to the two components, the approach also leads the researcher to define it beforehand. i.e., before she conducts the study, thereby reducing the chances that some sort of post-hoc definition will be used to justify the emotional impact used in the empirical finding.

Further, by relying on the suggested approach and clearly defining all the ways in which emotions might enter into decision making, new and interesting research venues should open up for researchers. For instance, more work is definitely needed in disentangling how emotions associated with different decision elements (i.e., action, task, and outcome) can impact decisions. The suggested approach makes it explicit that how an emotion enters into decision making can also be dependent on the decision element. This also relates to the fact that more work is needed to properly disentangle the impact of emotions which are related to the decision situations directly (e.g., integral emotions, as they were referred to). For instance, there has been some work suggesting that emotions people attach to decision actions can impact decisions, independent of the potential outcomes (Schlösser, Dunning, \& Fetchenhauer, 2013). However, the impact of integral emotions is more complicated than that. As George and Dane (2016) have stated, studying integral affect can be difficult, given that affect can be integral to the decisionmaking process, but that there is also the potential that the decision-making task itself differs across levels of integral affect. What will be the impact of these emotional reactions and what are the consequences to the decision?

Another potential research venue that emerges while following this approach is that it indirectly leads one to study how multiple emotional inputs impact decision making. Following the suggested approach it should become clear to researchers that emotions can enter decision making from several possible angles, paving the way for studying how multiple emotions impact decision making (cf. Västfjäll et al., 2016). Usually, research has focused on how a single 
emotional quality might impact decision making, however a more naturalistic way of approaching this ought to be aware of the fact that people might be confronted with multiple emotions when deciding, they could be exposed to multiple emotional cues or elicitors, or longer lasting emotional qualities might interact with qualities that are evoked more closely by the decision situation. For instance, how might a person’s negative mood interact with them expecting to feel regret if they choose a particular course of action?

Similarly, following the suggested approach, and focusing on the decision actor feature for instance, researchers can study how emotional reactions could impact decision making, dependent on whether somebody is making the decision or whether they are waiting on a decision by someone else.

The presented approach should also increase precision in which type of emotion is elicited given the specific interests of the researchers. The emotion and JDM literature is often plagued by problems concerning affective terminology. Terms like “affect”, “emotion”, “mood” and “feeling” are used interchangeably in empirical work (Kleinginna \& Kleinginna, 1981; Winkielman et al., 2007). As a result, one can end up with experiments manipulating negative mood by inducing sadness, even though sadness is a specific emotion with specific appraisals and effects on a decision situation (Lerner \& Keltner, 2000; Pollai, Hoelzl, Hahn, \& Hahn, 2011). Mood, on the other hand, also has certain qualities which make its effects on the decision unique (Raghunathan \& Pham, 1999; Schwarz \& Clore, 1983; Uddenberg \& Shim, 2015). The presented approach forces the researchers to be more precise. For instance, say a researcher is interested in the impact of high intensity emotions that have a known cause (i.e., high on the intensity and specificity feature). By following the suggested approach, it should be clear that 
mood ought not to be manipulated since it is generally long lasting and diffuse (Wyer, Clore, \& Isbell, 1999) meaning that, on the specificity feature it would have to be defined as low, not high.

Finally, the presented approach could provide researchers with a framework for more encompassing work. For instance, one might focus on a single feature of the affective component, but develop a research path where that single affective feature is verified across all the potential ways it can interact with the features of the decision component. For instance, one might focus on emotions which are low in awareness, but verify its impact dependent on the time of decision, decision element, and so on. That way, researchers could produce work that is intentionally wide-ranging covering at least one of the components, either decision or affect, in its entirety.

\section{Conclusion}

Emotions can enter into decision making in various ways. Usually, types of emotions have served as categorizing labels of the emotional impact. However, reviewing the state of how types of emotions have been presented over the years, we noticed several differences and a lack of a unified approach to the categorizations. This paper presents a review of types of emotions which has attempted to present the common types identified across the literature, while also presenting a new strategy of categorizing the way emotions can enter into decision making. By making several explicit suggestions for focusing on how the emotional impact relates to the decision and the affective quality, we believe that researchers can more easily categorize the emotional impact and post new and interesting empirical questions in the emotion and JDM domain. 


\section{References}

Ariely, D., \& Loewenstein, G. (2006). The heat of the moment: The effect of sexual arousal on sexual decision making. Journal of Behavioral Decision Making, 19(2), 87-98. https://doi.org/10.1002/bdm.501

Baumgartner, H., Pieters, R., \& Bagozzi, R. P. (2008). Future-oriented emotions: Conceptualization and behavioral effects. European Journal of Social Psychology, 38(4), 685-696. https://doi.org/10.1002/ejsp.467

Bechara, A. (1997). Deciding advantageous before knowing the advantagous strategy. Science, 275(1997), 1293-1294. https://doi.org/10.1126/science.275.5304.1293

Caruso, E. M., \& Shafir, E. (2006). Now that I think about it, i'm in the mood for laughs: Decisions focused on mood. Journal of Behavioral Decision Making, 19(2), 155-169. https://doi.org/10.1002/bdm.506

Charpentier, C. J., De Neve, J.-E., Li, X., Roiser, J. P., \& Sharot, T. (2016). Models of Affective Decision Making: How Do Feelings Predict Choice? Psychological Science, 27(6), 1-13. https://doi.org/10.1177/0956797616634654

Cohen, J. B., Pham, M. T., \& Andrade, E. B. (2008). The nature and role of affect in consumer behavior. In Handbook of consumer psychology (pp. 297-348). New York, NY: Taylor \& Francis Group. https://doi.org/10.4324/9780203809570

Connolly, T., \& Reb, J. (2012). Regret aversion in reason-based choice. Theory and Decision, 73(1), 35-51. https://doi.org/10.1007/s11238-011-9269-0

Damasio, A. R. (1994). Descartes’ Error: Emotion, Reason, and the Human Brain. New York, NY: Avon. https://doi.org/10.7202/051028ar

De Martino, B., Kumaran, D., Seymour, B., \& Dolan, R. J. (2006). Frames, biases, and rational 
decision-making in the human brain. Science (New York, N.Y.), 313(5787), 684-7. https://doi.org/10.1126/science.1128356

DeSteno, D., Li, Y., Dickens, L., \& Lerner, J. S. (2014). Gratitude: a tool for reducing economic impatience. Psychol Sci, 25(6), 1262-1267. https://doi.org/10.1177/0956797614529979

DeWall, C. N., Baumeister, R. F., Chester, D. S., \& Bushman, B. J. (2016). How Often Does Currently Felt Emotion Predict Social Behavior and Judgment? A Meta-Analytic Test of Two Theories. Emotion Review, 8(2), 136-143. https://doi.org/10.1177/1754073915572690

Dhar, R., \& Wertenbroch, K. (2000). Consumer Choice Between Hedonic and Utilitarian Goods. Journal of Marketing Research, 37(1), 60-71. https://doi.org/10.1509/jmkr.37.1.60.18718

Dunn, B. D., Galton, H. C., Morgan, R., Evans, D., Oliver, C., Meyer, M., ... Dalgleish, T. (2010). Listening to your heart. How interoception shapes emotion experience and intuitive decision making. Psychological Science, 21(12), 1835-1844.

https://doi.org/10.1177/0956797610389191

Dunning, D., Fetchenhauer, D., \& Schlösser, T. (2017). The varying roles played by emotion in economic decision making. Current Opinion in Behavioral Sciences, 15, 33-38.

https://doi.org/10.1016/j.cobeha.2017.05.006

Fredrickson, B. L., Kahneman, D., Hayes, A., \& Knopoff, K. (1993). Duration Neglect in Retrospective Evaluations of Affective Episodes. Journal of Personality and Social Psychology, 65(1), 44-55.

Gardner, M. P. (1985). Mood States and Consumer Behavior: A Critical Review. Journal of Consumer Research, 12(3), 281. https://doi.org/10.1086/208516

George, J. M., \& Dane, E. (2016). Affect, emotion, and decision making. Organizational Behavior and Human Decision Processes, 136, 47-55. 
https://doi.org/10.1016/j.obhdp.2016.06.004

Gollnisch, G., \& Averill, J. R. (1993). Emotional imagery: Strategies and correlates. Cognition \& Emotion, 7(5), 407-429. https://doi.org/10.1080/02699939308409196

Gorn, G., Tuan Pham, M., \& Yatming Sin, L. (2001). When Arousal Influences Ad Evaluation and Valence Does Not (and Vice Versa). Journal of Consumer Psychology, 11(1), 43-55. https://doi.org/10.1207/S15327663JCP1101_4

Haney, J. N., \& Euse, F. J. (1976). Skin conductance and heart rate responses to neutral, positive, and negative imagery: Implications for convert behavior therapy procedures. Behavior Therapy, 7(4), 494-503. https://doi.org/10.1016/S0005-7894(76)80169-4

Hastie, R. (2001). Problems for judgment and decision making. Annual Review of Psychology, 52(1), 653-683. https://doi.org/0066-4308/01/0201-0653

Hastie, R. (2001). Problems for Judgment and Decision Making. Annual Review of Psychology, 52(1), 653-683. https://doi.org/10.1146/annurev.psych.52.1.653

Jenkinson, P. M., Baker, S. R., Edelstyn, N. M. J., \& Ellis, S. J. (2008). Does autonomic arousal distinguish good and bad decisions? Healthy individuals’ the Iowa gambling task. Journal of Psychophysiology, 22(3), 141-149. https://doi.org/10.1027/0269-8803.22.3.141

Johnson, E. J., \& Tversky, A. (1983). Affect, generalization, and the perception of risk. Journal of Personality and Social Psychology, 45(1), 20-31. https://doi.org/10.1037/00223514.45.1.20

Kleinginna, P. R., \& Kleinginna, A. M. (1981). A categorized list of emotion definitions, with suggestions for a consensual definition. Motivation and Emotion, 5(4), 345-379. https://doi.org/10.1007/BF00992553

Koenigs, M., \& Tranel, D. (2008). Prefrontal cortex damage abolishes brand-cued changes in 
cola preference. Social Cognitive and Affective Neuroscience, 3(1), 1-6. https://doi.org/10.1093/scan/nsm032

Lambie, J. A., \& Marcel, A. J. (2002). Consciousness and the varieties of emotion experience: a theoretical framework. Psychological Review, 109(2), 219-259. https://doi.org/10.1037/0033-295X.109.2.219

Lang, P. J., Kozak, M. J., Miller, G. A., Levin, D. N., \& McLean, A. (1980). Emotional Imagery: Conceptual Structure and Pattern of Somato-Visceral Response. Psychophysiology, 17(2), 179-192. https://doi.org/10.1111/j.1469-8986.1980.tb00133.x

Lee, A. Y. Y., \& Sternthal, B. (1999). The Effects of Positive Mood on Memory. Journal of Consumer Research, 26(2), 115-127. https://doi.org/10.1086/209554

Lerner, J. S., \& Keltner, D. (2000). Beyond valence: Toward a model of emotion-specific influences on judgement and choice. Cognition \& Emotion, 14(4), 473-493. https://doi.org/10.1080/026999300402763

Lerner, J. S., \& Keltner, D. (2001). Fear, Anger, and Risk. Journal of Personality and Social Psychology, 81(1), 146-159. https://doi.org/10.1037/0022-3514.81.1.146

Lerner, J. S., Li, Y., Valdesolo, P., \& Kassam, K. S. (2015). Emotion and Decision Making. Annual Review of Psychology, 66(1), 799-823. https://doi.org/10.1146/annurev-psych010213-115043

Lerner, J. S., Li, Y., \& Weber, E. U. (2013). The financial costs of sadness. Psychol Science, 24(1), 72-79. https://doi.org/10.1177/0956797612450302

Lerner, J. S., \& Tiedens, L. Z. (2006). Portrait of the angry decision maker: How appraisal tendencies shape Anger's influence on cognition. Journal of Behavioral Decision Making, 19(2), 115-137. https://doi.org/10.1002/bdm.515 
Loewenstein, G. (1996). Out of Control: Visceral Influences on Behavior. Organizational Behavior and Human Decision Processes, 65(3), 272-292. https://doi.org/http://dx.doi.org/10.1006/obhd.1996.0028

Loewenstein, G. F., Weber, E. U., Hsee, C. K., \& Welch, N. (2001). Risk as feelings. Psychological Bulletin, 127(2), 267-286. https://doi.org/10.1037/0033-2909.127.2.267

Loewenstein, G., \& Lerner, J. S. (2003). The role of affect in decision making. In Handbook of affective science (Vol. 619, pp. 619-642). Retrieved from http://content.ksg.harvard.edu/lernerlab/pdfs/Loewenstein_and_Lerner_2003_Paper.pdf Loomes, G., \& Sugden, R. (1986). Disappointment and Dynamic Consistency in Choice under Uncertainty. Review of Economic Studies, 53(2), 271-282. https://doi.org/10.2307/2297651

Luce, M. F. (1998). Choosing to Avoid: Coping with Negatively Emotion-Laden Consumer Decisions. Journal of Consumer Research, 24(4), 409-433. https://doi.org/10.1086/209518

Maia, T. V, \& McClelland, J. L. (2004). A reexamination of the evidence for the somatic marker hypothesis: what participants really know in the Iowa gambling task. Proceedings of the National Academy of Sciences of the United States of America, 101(45), 16075-80. https://doi.org/10.1073/pnas.0406666101

Martinez, L. F., Zeelenberg, M., \& Rijsman, J. B. (2011). Regret, disappointment and the endowment effect. Journal of Economic Psychology, 32(6), 962-968. https://doi.org/10.1016/j.joep.2011.08.006

Mellers, B. A. (2001). Anticipated Emotions as Guides to Choice. Current Directions in Psychological Science, 10(6), 210-214. https://doi.org/10.1111/1467-8721.00151

Mellers, B. A., Schwartz, A., Ho, K., \& Ritov, I. (1997). Decision affect theory: emotional reactions to the outcomes of risky options. Psychological Science, 8(6), 423-429. 
https://doi.org/10.1111/j.1467-9280.1997.tb00455.x

Mikels, J. A., Cheung, E., Cone, J., \& Gilovich, T. (2013). The dark side of intuition: aging and increases in nonoptimal intuitive decisions. Emotion, 13(2), 189-195. https://doi.org/10.1037/a0030441

Mikels, J. a, Löckenhoff, C. E., Maglio, S. J., Goldstein, M. K., Garber, A., \& Carstensen, L. L. (2010). Following your heart or your head: focusing on emotions versus information differentially influences the decisions of younger and older adults. Journal of Experimental Psychology. Applied, 16(1), 87-95. https://doi.org/10.1037/a0018500

Pedroni, A., Frey, R., Bruhin, A., Dutilh, G., Hertwig, R., \& Rieskamp, J. (2017). The risk elicitation puzzle. Nature Human Behaviour. https://doi.org/10.1038/s41562-017-0219-x

Pham, M. T. (2007). Emotion and rationality: A critical review and interpretation of empirical evidence. Review of General Psychology, 11(2), 155-178. https://doi.org/10.1037/10892680.11.2.155

Pham, M. T., Cohen, J. B., Pracejus, J. W., \& Hughes, G. D. (2001). Affect Monitoring and the Primacy of Feelings in Judgment. Journal of Consumer Research, 28(2), 167-188. https://doi.org/10.1086/322896

Phelps, E. A., Lempert, K. M., \& Sokol-Hessner, P. (2014). Emotion and Decision Making: Multiple Modulatory Neural Circuits. Annual Review of Neuroscience, 37(1), 263-287. https://doi.org/10.1146/annurev-neuro-071013-014119

Pollai, M., Hoelzl, E., Hahn, L., \& Hahn, A. (2011). The influence of anticipated emotions on consumer decisions examining the role of product type and belief in adaptation. Zeitschrift Fur Psychologie / Journal of Psychology, 219(4), 238-245. https://doi.org/10.1027/21512604/a000078 
Raghunathan, R., \& Pham, M. T. (1999). All Negative Moods Are Not Equal: Motivational Influences of Anxiety and Sadness on Decision Making. Organizational Behavior and Human Decision Processes, 79(1), 56-77. https://doi.org/10.1006/obhd.1999.2838

Ratner, R. K., \& Herbst, K. C. (2005). When good decisions have bad outcomes: The impact of affect on switching behavior. Organizational Behavior and Human Decision Processes, 96(1), 23-37. https://doi.org/10.1016/j.obhdp.2004.09.003

Rottenstreich, Y., \& Hsee, C. K. (2001). Money, kisses, and electric shocks: on the affective psychology of risk. Psychological Science, 12(3), 185-90. https://doi.org/10.1111/14679280.00334

Rottenstreich, Y., \& Shu, S. (2004). The connections between affect and decision making: Nine resulting Phenomena. In D. J. Koehler \& N. Harvey (Eds.), Blackwell handbook of judgment and decision making (pp. 444-463). Blackwell Publishing Ltd.

Rozin, P., Millman, L., \& Nemeroff, C. (1986). Operation of the Laws of Sympathetic Magic in Disgust and Other Domains. Journal of Personality and Social Psychology, 50(4), 703-712. https://doi.org/10.1037/0022-3514.50.4.703

Russell, J. A. (2003). Core affect and the psychological construction of emotion. Psychological Review, 110(1), 145-72. https://doi.org/10.1037/0033-295X.110.1.145

Scheibehenne, B., \& von Helversen, B. (2014). Selecting decision strategies: The differential role of affect. Cognition \& Emotion, $0(0), 1-10$. https://doi.org/10.1080/02699931.2014.896318

Scherer, K. R. (1999). On the Sequential Nature of Appraisal Processes: Indirect Evidence from a Recognition Task. Cognition \& Emotion, 13(6), 763-793. https://doi.org/10.1080/026999399379078 
Schlösser, T., Dunning, D., \& Fetchenhauer, D. (2013). What a Feeling: The Role of Immediate and Anticipated Emotions in Risky Decisions. Journal of Behavioral Decision Making, 26(1), 13-30. https://doi.org/10.1002/bdm.757

Schwarz, N. (2000). Emotion, cognition, and decision making. Cognition \& Emotion, 14(4), 433-440. https://doi.org/10.1080/026999300402745

Schwarz, N., \& Clore, G. (2003). Mood as information: 20 years later. Psychological Inquiry: An International Journal for the Advancement of Psychological Theory, 14(3), 296-303. https://doi.org/10.1207/S15327965PLI1403\&4_20

Schwarz, N., \& Clore, G. L. (1983). Mood, misattribution, and judgments of well-being: Informative and directive functions of affective states. Journal of Personality and Social Psychology, 45(3), 513-523. https://doi.org/10.1037/0022-3514.45.3.513

Shiv, B., Loewenstein, G., Bechara, A., Damasio, H., \& Damasio, A. R. (2005). Investment behavior and the negative side of emotion. Psychological Science, 16(6), 435-439. https://doi.org/10.1111/j.0956-7976.2005.01553.x

Slovic, P., Peters, E., Finucane, M. L., \& MacGregor, D. G. (2005). Affect, Risk, and Decision Making. Health Psychology, 24(4, Suppl), S35-S40. https://doi.org/10.1037/02786133.24.4.S35

Smith, C., \& Ellsworth, P. C. (1985). Patterns of cognitive appraisal in emotion. Journal of Personality and Social Psychology, 48(July), 813-838. https://doi.org/10.1037/00223514.48.4.813

Sunstein, C. R., \& Llewellyn, K. N. (2003). Terrorism and Probability Neglect. The Journal of Risk and Uncertainty, 26(3), 121-136. https://doi.org/10.1023/A:1024111006336

Uddenberg, S., \& Shim, W. M. (2015). Seeing the World Through Target-Tinted Glasses: 
Positive Mood Broadens Perceptual Tuning. Emotion, 15(3), 319-328. https://doi.org/10.1037/emo0000029

Van de Calseyde, P. P. F. M., Keren, G., \& Zeelenberg, M. (2014). Decision time as information in judgment and choice. Organizational Behavior and Human Decision Processes, 125(2), 113-122. https://doi.org/10.1016/j.obhdp.2014.07.001

Vastfjall, D., \& Slovic, P. (2013). Cognition and emotion in judgment and decision making. In D. Robinson, Michael, R. Watkins, Edward, \& E. Harmon-Jones (Eds.), Handbook of cognition and emotion (pp. 252-271). New York, NY: Guilford Press.

Västfjäll, D., Slovic, P., Burns, W. J., Erlandsson, A., Koppel, L., Asutay, E., \& Tinghög, G. (2016). The arithmetic of emotion: Integration of incidental and integral affect in judgments and decisions. Frontiers in Psychology, 7(MAR). https://doi.org/10.3389/fpsyg.2016.00325

Wälde, K., \& Moors, A. (2017). Current Emotion Research in Economics. Emotion Review, 9(3), 271-278. https://doi.org/10.1177/1754073916665470

Winkielman, P., Knutson, B., Paulus, M., \& Trujillo, J. L. (2007). Affective influence on judgments and decisions: Moving towards core mechanisms. Review of General Psychology, 11(2), 179-192. https://doi.org/10.1037/1089-2680.11.2.179

Wyer, R. S., Clore, G. L., \& Isbell, L. M. (1999). Affect and Information Processing. Advances in Experimental Social Psychology, 31, 1-77. https://doi.org/10.1016/S00652601(08)60271-3

Yang, Z., Saini, R., \& Freling, T. (2015). How Anxiety Leads to Suboptimal Decisions Under Risky Choice Situations. Risk Analysis, 35(10), 1789-1800. https://doi.org/10.1111/risa.12343

Yik, M. S. M., Russell, J. A., \& Barrett, L. F. (1999). Structure of self-reported current affect: 
Integration and beyond. Journal of Personality and Social Psychology, 77(3), 600-619. https://doi.org/10.1037/0022-3514.77.3.600

Zeelenberg, M. (1999). Anticipated refret, expected feedback, and behavioural decision making. Journal of Behavioral Decision Making, 12(2), 93-106.

Zeelenberg, M., Van Dijk, W. W., \& Manstead, A. S. R. (2000). On bad decisions and disconfirmed expectancies: The psychology of regret and disappointment. Cognition \& ..., 14(4), 521-541. https://doi.org/10.1080/026999300402781 
Table 1. The classifications of types of emotion in recent reviews of emotion and JDM. The “\#” indicates the number of times the review has been cited, according to Google Scholar (at the time of this writing).

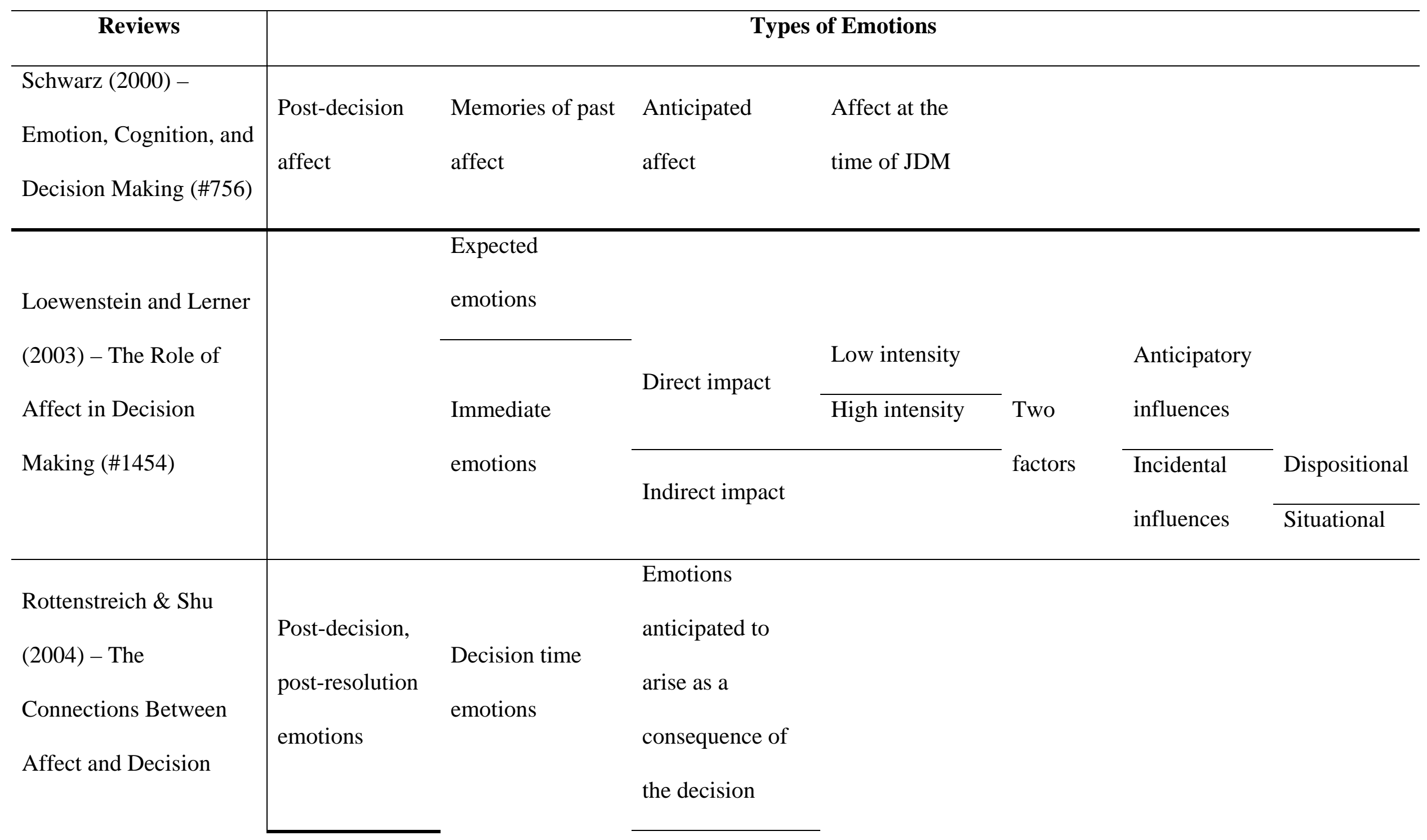




\begin{tabular}{|c|c|c|c|}
\hline & & & \\
\hline Making: Nine Resulting & & Emotions directly & Anticipatory \\
\hline Phenomena (\#43) & PUst-uecision, & connected to & emotions \\
\hline & emotions & $\begin{array}{l}\text { making a } \\
\text { decision }\end{array}$ & $\begin{array}{l}\text { Process-induced } \\
\text { emotions }\end{array}$ \\
\hline & & . & $\begin{array}{l}\text { Feelings due to } \\
\text { exposure to } \\
\text { object. }\end{array}$ \\
\hline Cohen, Pham, and & & Integral affect & $\begin{array}{l}\text { Representation } \\
\text { of the object. }\end{array}$ \\
\hline Andrade (2008) - The & & & Internally \\
\hline Nature and Role of & & & generated. \\
\hline Affect in Consumer & & & Mood effects on \\
\hline Behavior (\#318) & & & behavior \\
\hline & & Incidental affect & $\begin{array}{l}\text { Dispositions and } \\
\text { temperament. }\end{array}$ \\
\hline & & & $\begin{array}{l}\text { Contextual } \\
\text { stimuli }\end{array}$ \\
\hline
\end{tabular}




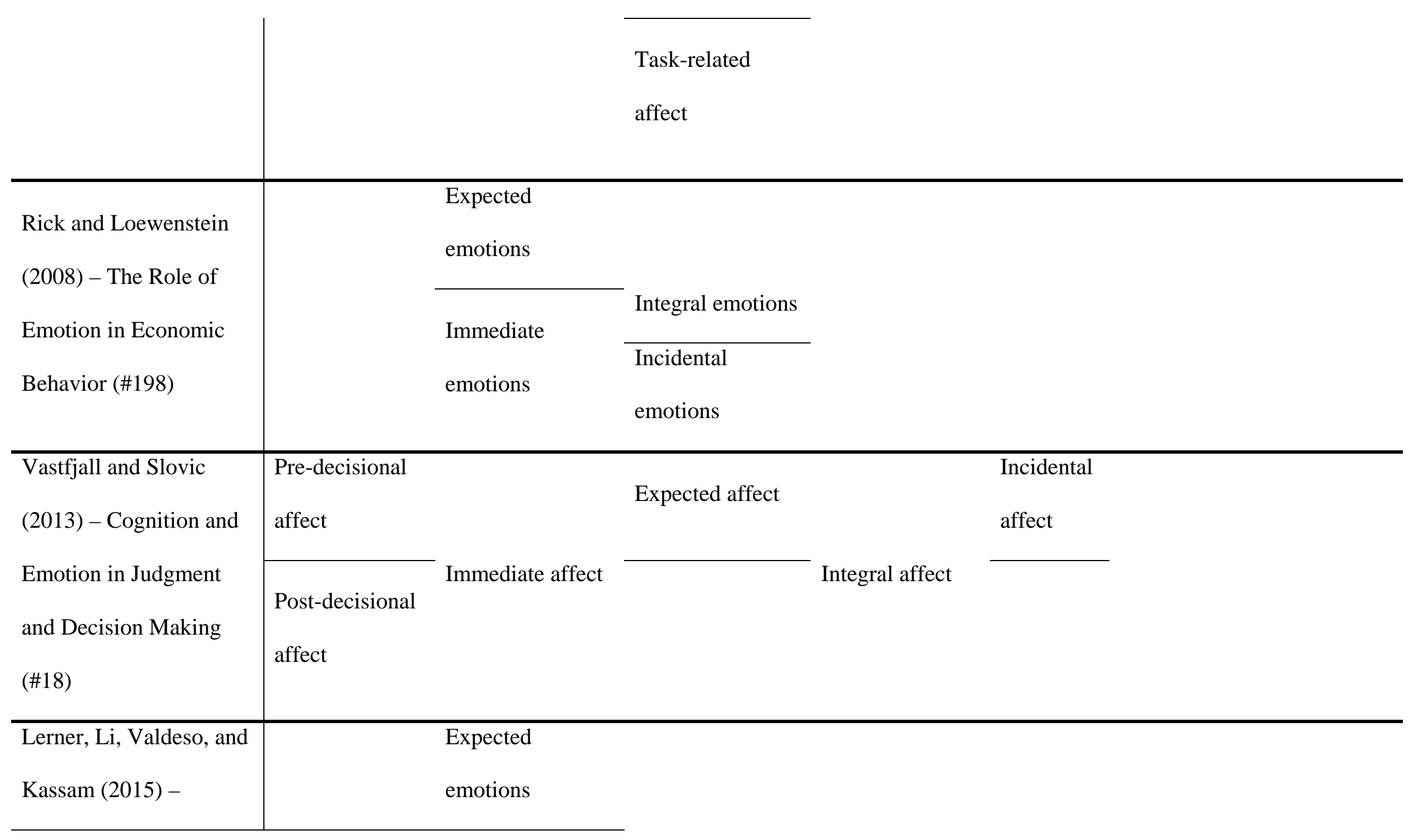




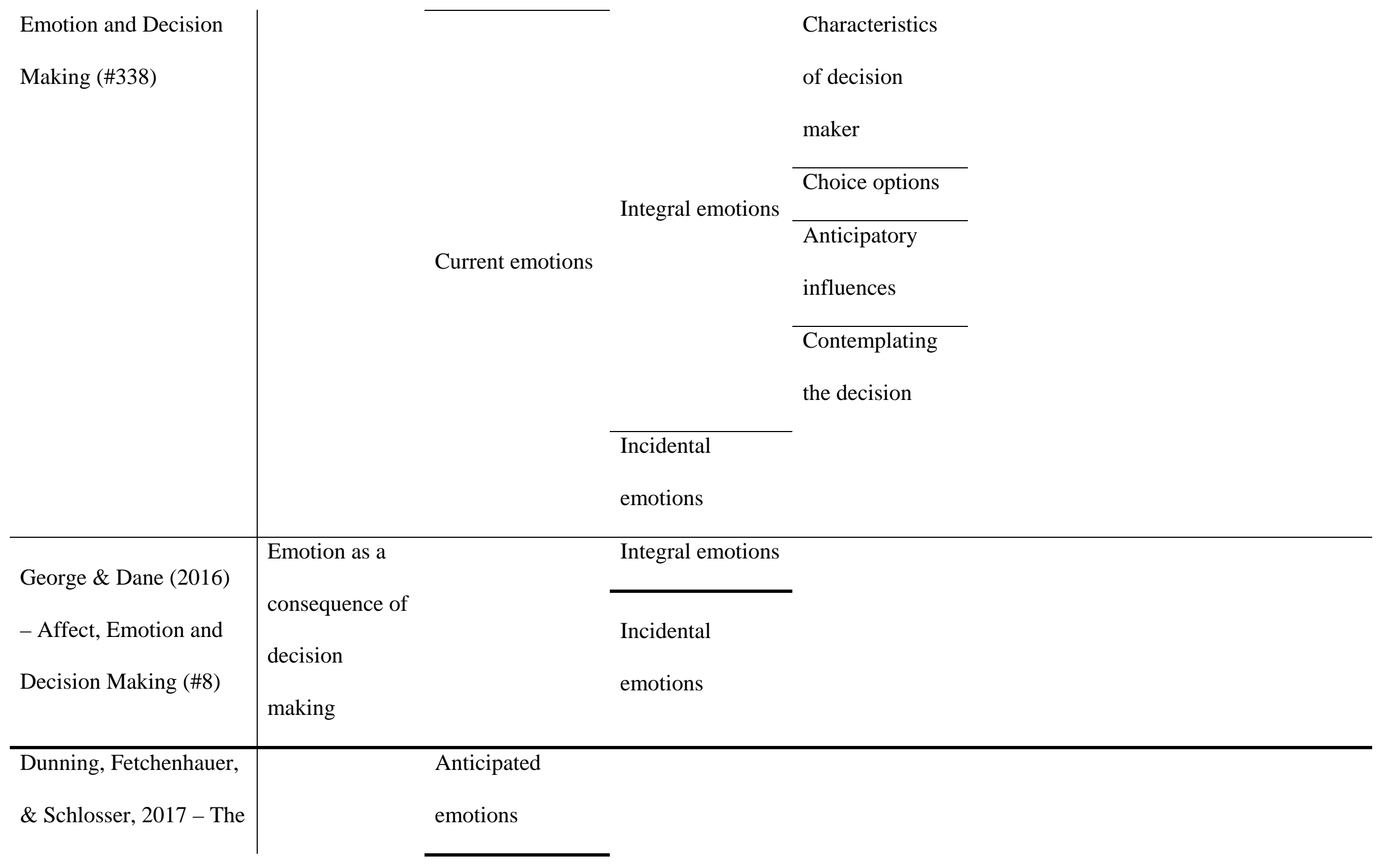




\begin{tabular}{l|lll} 
varying roles played by & & Background \\
emotion in economic & & Immediate & emotions \\
decision making (\#1) & & emotions & Action-related \\
\hline Walde \& Moors, 2017 - & & Anticipated & \\
Current emotion & Ex post & emotions & Ex \\
research in economics & emotions & ante/anticipatory & \\
$(\# 1)$ & & emotions \\
\hline \hline
\end{tabular}


Table 2. A component-based categorization of types of emotions (i.e., how emotions might enter into decision making.

\begin{tabular}{ccc}
\hline Component & Feature & Range \\
\hline \multirow{2}{*}{ Affect } & Phenomenology & Felt vs. Not Felt \\
& Awareness & Low vs. High \\
& Intensity & Low vs. High \\
Specificity & Low vs. High \\
\hline Decision & Time of decision & Pre vs. Post decision \\
& Decision situation relationship & Unrelated vs. Caused by \\
& Decision component & Action vs. Outcome \\
& Decision actor & Receiver vs. Decider \\
\hline \hline
\end{tabular}

